\title{
Clinical Scoring Systems in the Management of Suspected Appendicitis in Children
}

\author{
Graham Thompson \\ Pediatric Emergency Medicine \\ University of Calgary, Alberta Children's Hospital \\ Canada
}

\section{Introduction}

Abdominal pain is a common problem in children presenting to the Emergency Department (ED) and though the differential diagnosis is expansive, appendicitis is the most common surgical emergency of childhood. While many children present with classical findings of right lower quadrant (RLQ) pain associated with nausea or vomiting and fever, subtle features and difficult examinations can make identifying appendicitis in a child challenging, leaving Health Care Providers struggling to distinguish this surgical emergency from less urgent conditions. Appendicitis is a progressive condition making early recognition essential in limiting morbidity and mortality. While some suggest Diagnostic Imaging (DI) as a routine screen for all children with abdominal pain, ED wait times, fiscal restraints and increasing concern related to radiation exposure require a more prudent, selective approach to identifying the child with suspected appendicitis. Clinical Scoring Systems (CSSs) have been developed to assist clinicians in appropriately stratifying a child's clinical risk of having appendicitis. This chapter reviews the literature and reports on the experience of a tertiary care Pediatric Emergency Department (PED) in incorporating a clinical score into a Clinical Pathway in order to stratify children into High/Moderate/Low risk for appendicitis, thus guiding management and departmental patient flow.

\section{What are Clinical Scoring Systems?}

An increase in the use of Clinical Prediction Rules (CPRs) to improve diagnostic accuracy has occurred over the last 2 decades. CPRs are tools that use specific criteria in order to establish probabilities of outcomes or to assist in management decisions. Some researchers have distinguished 3 types of CPRs; Diagnostic CPRs which focus on factors related to arriving at a clinical diagnosis; Prognostic CPRs which predict outcomes; and Prescriptive CPRs which provide recommendations for clinical intervention.(Beattie \& Nelson, 2006) CPRs have been defined as decision-making tools that include 3 or more variables obtained from the history, physical examination or basic diagnostic tests in order to assist the clinician in decision making.(Laupacis, Sekar, \& I. G. Stiell, 1997) 
The format of a CPR can be variable, depending on the purpose. Some require fulfillment of a complete set of criteria in order to direct management. Others assign values to weighted criteria, the summation of which provides a score. These are often known as Clinical Scoring Systems (CSSs). Even within CSSs, several categories can be determined. Some CSSs are dichotomous, utilizing a cutoff value above which an action is recommended or an outcome is expected. For example, surgical intervention may be recommended for a certain validated score over 6. Others CSSs lean more toward a continuous nature to provide graded risk stratification. A simple example may stratify a patient to low risk of a disease process for scores of 1-2, moderate risk for scores of 3-5 and high risk for scores of 6-7.

While many CSSs exist, not all have been appropriately developed or evaluated. In the process of evaluation, one must consider several factors including the internal validity, accuracy, external validity, sensibility and potential impact (Beattie \& Nelson, 2006). Table 1 details some factors to consider when assessing a Clinical Scoring System.

McGinn et al have proposed a 4-level hierarchy to assist health care providers in determining the strength of CPRs and CSSs. Those that have been rigorously tested, including impact analysis, are deemed Level 1, while those that have simply been derived but not tested are Level 4 (McGinn et al., 2000). Ian Stiell, well known for the Ottawa Ankle Rules and the Canadian CT Head Rules (I. G. Stiell et al., 1992)(I. G. Stiell et al., 1993)(I. Stiell, 2001)(I. G. Stiell et al., 2001), created a checklist for assessing the developmental rigor of CPRs, including evaluation of clinical need, derivation methodology, prospective validation, successful implementation into practice, cost-effectiveness and dissemination strategies. (Stiell 1999).

\begin{tabular}{|l|l|}
\hline $\begin{array}{l}\text { Assessment } \\
\text { Criterion }\end{array}$ & Questions to Ask when evaluating a Clinical Scoring System \\
\hline \multirow{3}{*}{ Internal Validity } & $\begin{array}{l}\text { How was the Score derived? } \\
\text { How well defined are the criterion? } \\
\text { What is the inter- and intra- rater reliability of the Score? } \\
\text { How was the Score Validated? } \\
\text { Has the Score been evaluated for Impact? }\end{array}$ \\
\hline Accuracy & $\begin{array}{l}\text { What are the sensitivity, specificity, likelihood ratios and predictive } \\
\text { values of the Score? }\end{array}$ \\
\hline External Validity & Is the Score generalizable to my patient population? \\
\hline \multirow{5}{*}{ Sensibility } & $\begin{array}{l}\text { How many criteria are included in the Score? } \\
\text { How accessible are the criteria elements? } \\
\text { Are the criteria time-sensitive? } \\
\text { How easy is the Score to calculate? Do I need computer assistance? } \\
\text { Can all key stakeholders accurately and consistently apply the } \\
\text { Score? (Are responses reproducible?) }\end{array}$ \\
\hline Potential Impact & $\begin{array}{l}\text { Will implementation of the Score improve my diagnostic accuracy? } \\
\text { How will patient flow in my health care environment be impacted } \\
\text { by the Score? } \\
\text { Will implementation of the Score be consistent with other } \\
\text { departmental processes? } \\
\text { How will other key stakeholders be affected by the implementation } \\
\text { of the Score? }\end{array}$ \\
\hline
\end{tabular}

Table 1. Factors for determining the appropriateness of a Clinical Scoring System 


\section{Why use Clinical Scoring Systems?}

Making wise, educated decisions is the cornerstone of good medical practice and often involves estimating the probability of an event. Inherent to all medical decisions is an assessment of potential risk and benefit. Risk tolerance within a clinical setting is dependent on the key stakeholders involved, for example the health care providers, the patients, the general public, the health care organization and policy makers. For a clinician, factors such as personality traits, quality and quantity of practice, experience with recent adverse events or near misses, fears of litigation and external stressful events may impact risk tolerance.

Risk assessment requires at least some basic knowledge of statistics, though mastery is far from needed. While terms such as sensitivity and specificity are familiar to many medical staff they are not as useful as other concepts. An understanding of Pre- and Post- Test likelihoods, Positive- and Negative- Predictive Values (PPV, NPV), Positive- and NegativeLikelihood Ratios (PLR, NLR) and Accuracy impact on the interpretation of results.

There are significant variations in clinical practice and outcomes, at national, regional and even local levels in a number of conditions and appendicitis is amongst them. A number of studies have demonstrated practice variation, as well as the impact of variation on clinical outcome measures (Chang, Ng, Y.-C. Chen, J.-C. Chen, \& Yen, 2010)(Goldman et al., 2009)(Plint et al., 2004)(Richer et al., 2010)(Jain, Elon, Johnson, Frank, \& Deguzman, 2010). While practice variation results in patient outcome differences, standardization of practice based on the best evidence can result in improved care (Eitel, Rudkin, Malvehy, Killeen, \& Pines, 2010). Numerous studies have demonstrated the efficacy of Evidence Based Clinical Algorithms (EBCA) such as pathways and protocols in reducing delays in time-sensitive medication administration, reducing unwarranted radiation exposure and reducing mortality (Rivers et al., 2001)(Francis 2010, Osmond 2010,). Integrating CSSs into EBCA is key to standardizing patient care in an effort to improve global and individual health outcomes.

\section{The literature search strategy}

To obtain complete information related to CSSs for suspected appendicitis in children, a formal literature review of common scientific databases was performed by the Health Information Network Calgary, University of Calgary, Alberta, Canada. Multiple databases were searched including Medline, Embase, Cochrane, PubMed, CINAHL Plus and Academic Search Complete. The following terms were utilized in the search: appendicitis, acute appendicitis, clinical decision rule, clinical prediction rule, prediction, score, and risk stratification. Search strategies limited the results to those published between 1980 and 2011 and included all children aged 0 - 18 years (infant, preschool, school aged, adolescent, all child).

Abstracts of the above search strategy were reviewed, refining the final manuscript database to those relevant to the current topic. Two hundred sixty six references were reviewed. Thirty-six articles were retrieved for inclusion in this review. Reference lists of these manuscripts were examined and any additional citations relevant to the topic were added.

\section{Clinical Scoring Systems for suspected appendicitis in children}

Over the last 3 decades, a number of CSSs have been developed to assist the clinician in assessing patients presenting with abdominal pain and suspected appendicitis. Several of 
these scores were specifically derived for children, while others were developed for adults or mixed populations and subsequently validated in children. The best known, such as the Alvardo Score and the Pediatric Appendicitis score, have been studied at length. Lesser known scores such as Kharbanda's Low Risk Score, the Lindberg Score, and the Ohmann Sore, among others, are listed in Table 2. Most Scoring Systems include a combination of Historical, Clinical and Laboratory measures. Each of these scores will be reviewed in detail.

\begin{tabular}{|l|}
\hline Alvarado Score (MANTRELS) \\
\hline Pediatric Appendicitis Score (Samuel) \\
\hline Low Risk for Appendicitis Score (Kharbanda) \\
\hline Lintula Score \\
\hline Eskelinen Score \\
\hline Fenyo - Lindberg Score \\
\hline Ohmann Score \\
\hline Christian Score \\
\hline RIPASA Score \\
\hline
\end{tabular}

Table 2. Clinical Scoring Systems used in the Diagnosis of Appendicitis in children

Care is needed when evaluating studies of CSSs. Several studies include children and adults and some have few children. Populations may also differ; some studies include all-comers to the ED with abdominal pain whilst others include only those with suspected appendicitis, still others include those in whom a surgical consult was obtained and finally, some are limited to those children who had an appendectomy. Additionally, the medical specialty, level of training and experience of the staff performing Score assessments may also have a significant impact on generalizability (Emergency Physician vs. Surgeon, Senior Trainee vs. Attending Staff). Those studies that enroll prospectively are obviously more robust than retrospective analyses. And finally, some studies use modifications to a Score criteria (e.g. dropping a criteria) or to the threshold level (e.g. standard Alvarado Score threshold for probable appendicitis is $\geq 7$, but some studies use a cutoff of 6).

In light of some of these potential biases, Ohmann et al re-evaluated data from 10 published CSSs for appendicitis to determine their performance in meeting predefined quality criteria. Subsequently, they prospectively collected data on 1254 patients with acute abdominal pain from 6 different sites in order to evaluate the same Scores. The predefined quality criteria included a) initial negative appendectomy rate $<15 \%$; b) potential perforation rate $<35 \%$; c) initial missed perforation rate $<15 \%$ and d) missed appendicitis rate $<5 \%$. Four of the original derivation studies met at least one quality criteria, however, when applied to the prospective evaluation, none of the 10 Scores were successful in meeting the predefined quality criteria. Ohmann et al concluded that significant bias existed in the derivation of the Scores, as mentioned in the paragraph above. (Ohmann, Yang, \& Franke, 1995)

\subsection{The Alvarado Score (MANTRELS)}

In 1986, Alvarado published what is now one of the most well-known and studied appendicitis scores (Alvarado, 1986). This retrospective study of 305 patients admitted for suspected appendicitis evaluated common clinical and laboratory findings in relation to pathologically proven acute appendicitis. 277 patients were eligible for analysis. 
Eight criteria were chosen for inclusion in the diagnostic score, weighted to represent joint probability of disease. The Diagnostic criteria for the Alvarado Score are shown in Table 3. Right Lower Quadrant (RLQ) Pain and a Left Shift were found to be the most prevalent, thus receiving 2 points each, while each of the remaining criteria were attributed 1 point. This initial study included both adults and children, with an age range of 4 to 80 years (mean 25.3). An Alvarado Score of $\geq 7$ was considered high risk for appendicitis. Though not explicitly stated in the study, this threshold value had a sensitivity of $81 \%$ and a specificity of $74 \%$. Several elements of the score have been criticised, particularly the threshold for fever $(37.3 \mathrm{C})$ and the availability of peripheral cell count differentials at some health centres, prompting some investigators to modify the score (see below).

\begin{tabular}{|ll|ll|}
\hline Alvarado Score & & $\begin{array}{l}\text { Pediatric Appendicitis } \\
\text { Score }\end{array}$ \\
\hline Diagnostic Criteria & Value & Diagnostic Criteria & Value \\
\hline Migration of pain to RLQ & 1 & Migration of Pain & 1 \\
$\begin{array}{l}\text { Anorexia/ Acetone in urine } \\
\text { (i.e. ketones) }\end{array}$ & 1 & Anorexia & 1 \\
Nausea-Vomiting & 1 & Nausea/Emesis & 1 \\
Tenderness in RLQ & 2 & Tenderness in RLQ & 2 \\
Rebound Pain & 1 & Cough/Percussion & 2 \\
Elevation of Temperature & 1 & Tenderness & \\
$(\geq 37.3$ C) & 2 & Pyrexia (not defined) & 1 \\
Leukocytosis (> 10 000) & 2 & Leukocytosis (> 10 000) & 1 \\
Shift to Left (> 75\%) & 1 & Neutrophilia & 1 \\
\hline Total Score & $\mathbf{1 0}$ & Total Score & $\mathbf{1 0}$ \\
\hline
\end{tabular}

Table 3. Comparison of Diagnostic Criteria between the Alvarado Score (MANTRELS) and the Pediatric Appendicitis Score (Samuel Score)

Numerous studies have examined the Alvarado Score, particularly in children. (Table 4) Bond et al prospectively studied 187 children aged $2-17$ years with suspected appendicitis, of which 143 were admitted. Using Alvarado's cutoff score of 7 to indicate the need for surgery, the authors found a sensitivity and specificity of $90 \%$ and $72 \%$ respectively, with a negative appendectomy rate of $17 \%$. Lower cutoff scores (5 or 6) demonstrated improved sensitivity, but corresponding reductions in specificity, as expected. Subgroup analysis showed the score to be least accurate in preschool children, corresponding to the clinical experience of many health care providers, though overall numbers in this age group were limited. The authors concluded that the Alvarado Score failed to achieve their predetermined standard for accuracy, however, this was set quite high at $99.5 \%$ sensitivity. (Bond, Tully, Chan, \& Bradley, 1990)

A retrospective study of children under 14 years by Hsiao et al confirmed Alvarado's data showing that RLQ tenderness and a left shift were the most prevalent signs in those with pathologically proven appendicitis. Children with Alvarado Scores $\geq 7$ were statistically more likely to have appendicitis than controls. Overall sensitivity and specificity for an Alvarado Score $>=7$ were $60 \%$ and $61 \%$ respectively. (Hsiao, Lin, \& D.-F. Chen, 2005) 


\begin{tabular}{|c|c|c|c|c|c|c|c|c|c|c|c|c|c|c|}
\hline Study & Year & Population & Ages & Design & $\mathrm{T}+$ & $\mathrm{F}+$ & F- & $T-$ & Sens & Spec & PPV & NPV & Acc & Notes \\
\hline Alvarado & 1986 & $\begin{array}{l}305 \text { suspected } \\
\text { appendicitis } \\
277 \text { included }\end{array}$ & $\begin{array}{l}4 \text { to } 80 \\
\text { years }\end{array}$ & Retrospective & 184 & 13 & 43 & 37 & $81 \%$ & $74 \%$ & $93 \%$ & $46 \%$ & $80 \%$ & $\begin{array}{l}\text { Derivation } \\
\text { Study }\end{array}$ \\
\hline Bond & 1990 & $\begin{array}{l}189 \text { suspected } \\
\text { appendicitis } \\
143 \text { included }\end{array}$ & $\begin{array}{l}2 \text { to } 17 \\
\text { years }\end{array}$ & Prospective & 103 & 21 & 12 & 52 & $90 \%$ & $71 \%$ & $83 \%$ & $81 \%$ & $82 \%$ & \\
\hline Owen & 1992 & $\begin{array}{l}215 \text { suspected } \\
\text { appendicitis } \\
70 \text { children }\end{array}$ & $\begin{array}{l}\text { Not } \\
\text { defined }\end{array}$ & Prospective & 40 & 5 & 3 & 22 & $93 \%$ & $81 \%$ & $89 \%$ & $88 \%$ & $89 \%$ & $\begin{array}{l}\text { Sub-group } \\
\text { analysis }\end{array}$ \\
\hline Kalan & 1994 & $\begin{array}{l}49 \text { suspected } \\
\text { appendicitis } \\
11 \text { children }\end{array}$ & $\begin{array}{l}\text { Not } \\
\text { defined }\end{array}$ & Prospective & 11 & 0 & 0 & 0 & $100 \%$ & N/A & $100 \%$ & $\mathrm{~N} / \mathrm{A}$ & $100 \%$ & $\begin{array}{l}\text { Modified } \\
\text { Alvarado - } \\
\text { No Left Shift }\end{array}$ \\
\hline Macklin & 1997 & $\begin{array}{l}118 \text { suspected } \\
\text { appendicitis }\end{array}$ & $\begin{array}{l}4 \text { to } 14 \\
\text { years }\end{array}$ & Prospective & 29 & 17 & 9 & 63 & $76 \%$ & $79 \%$ & $63 \%$ & $88 \%$ & $78 \%$ & $\begin{array}{l}\text { Modified } \\
\text { Alvarado - } \\
\text { No Left Shift }\end{array}$ \\
\hline Hsiao & 2005 & $\begin{array}{l}222 \text { suspected } \\
\text { appendicitis }\end{array}$ & $\begin{array}{l}<14 \\
\text { years }\end{array}$ & Retrospective & 66 & 45 & 43 & 68 & $61 \%$ & $60 \%$ & $59 \%$ & $61 \%$ & $60 \%$ & \\
\hline Schneider & 2007 & $\begin{array}{l}821 \text { suspected } \\
\text { appendicitis } \\
588 \text { included }\end{array}$ & $\begin{array}{l}3 \text { to } 21 \\
\text { years }\end{array}$ & Prospective & 142 & 75 & 55 & 316 & $72 \%$ & $81 \%$ & $65 \%$ & $85 \%$ & $78 \%$ & $\begin{array}{l}\text { Alvarado } \\
\text { /PAS } \\
\text { comparison }\end{array}$ \\
\hline Shreef & 2010 & $\begin{array}{l}350 \text { suspected } \\
\text { appendicitis }\end{array}$ & $\begin{array}{l}8 \text { to } 14 \\
\text { years }\end{array}$ & Prospective & 114 & 37 & 18 & 181 & $86 \%$ & $83 \%$ & $75 \%$ & $91 \%$ & $84 \%$ & $\begin{array}{l}\text { Based on } \\
\text { threshold }=7 \\
\text { Paper reports } \\
\text { threshold }=6\end{array}$ \\
\hline Escriba & 2011 & $\begin{array}{l}112 \text { suspected } \\
\text { appendicitis } \\
99 \text { included }\end{array}$ & $\begin{array}{l}4 \text { to } 18 \\
\text { years }\end{array}$ & Prospective & $?$ & $?$ & $?$ & ? & $90 \%$ & $91 \%$ & $88 \%$ & $93 \%$ & ? & $\begin{array}{l}\text { Alvarado/ } \\
\text { PAS } \\
\text { comparison } \\
\text { Threshold } \\
\text { used was } 6\end{array}$ \\
\hline Rezak & 2011 & $\begin{array}{l}61 \text { suspected } \\
\text { appendicitis } \\
59 \text { included }\end{array}$ & $\begin{array}{l}3 \text { to } 16 \\
\text { years }\end{array}$ & Retrospective & ? & $?$ & $?$ & ? & $92 \%$ & $82 \%$ & ? & ? & $92 \%$ & $\begin{array}{l}\text { Alvarado/ } \\
\text { PAS } \\
\text { comparison }\end{array}$ \\
\hline Chong & 2011 & $\begin{array}{l}200 \text { suspected } \\
\text { appendicitis } \\
192 \text { included }\end{array}$ & $\begin{array}{l}\text { Adults } \\
\& \\
\text { children, } \\
\text { not } \\
\text { defined }\end{array}$ & Prospective & 69 & 11 & 32 & 80 & $68 \%$ & $87 \%$ & $86 \%$ & $71 \%$ & $86 \%$ & $\begin{array}{l}\text { Alvarado } \\
\text { /RIPASA } \\
\text { comparison }\end{array}$ \\
\hline Mandeville & 2011 & $\begin{array}{l}487 \text { diagnosed } \\
\text { appendicitis } \\
287 \text { enrolled }\end{array}$ & $\begin{array}{l}4 \text { to } 16 \\
\text { years }\end{array}$ & Prospective & $?$ & $?$ & $?$ & ? & $76 \%$ & $72 \%$ & $76 \%$ & $72 \%$ & ? & In Press \\
\hline
\end{tabular}

T+ True Positive, F+ False Positive, F- False Negative, T- True Negative, Sens Sensitivity, Spec Specificity, PPV Positive Predictive Value, NPV Negative Predictive Value, Acc Accuracy, ? data not provided, N/A not applicable

Table 4. Summary of Studies Evaluating the Alvarado Score in the Pediatric Population

A higher sensitivity and specificity was found by Rezak et al in their retrospective study (92\% and $82 \%$ respectively). Sixty-one children aged 3 to 16 years with suspected appendicitis had CT evaluation. This study suggested a $27 \%$ reduction in CT scanning would occur had children with scores $>7$ been managed directly by appendectomy without 
CT evaluation. High sensitivity and specificity were maintained, at $100 \%$ and $97 \%$ respectively, suggesting that surgical intervention was best suited to children with an Alvarado Score of 8-10, while those with scores of 5-7 be further evaluated with imaging studies (Rezak, Abbas, Ajemian, Dudrick, \& Kwasnik, 2011).

In a mixed pediatric-adult population, Owen et al prospectively evaluated 215 patients, 70 of whom were children. In this pediatric subgroup analysis, sensitivity and specificity were $93 \%$ and $81 \%$ (Owen 1992).

Shreef et al recently performed a dual-centre prospective study, reviewing 350 children aged 8 to 14 years. Interestingly, their reported statistical analysis was based on an Alvarado threshold of 6, and was based upon 2 different outcomes; 1 ) performance of appendectomy and 2) histology. Using the standard threshold of 7 and including all comers related to histologic diagnosis, the sensitivity and specificity were $86 \%$ and $83 \%$ respectively (Shreef, Waly, Abd-Elrahman, \& Abd Elhafez, 2010).

Several attempts have been made to modify the Alvarado Score to improve its accuracy. Macklin et al sought to simplify the Alvarado Score by eliminating the criteria for left shift (Modified Score total 9), as done by Kalan in a mixed adult/pediatric study. Children aged 4-14 years were enrolled, demonstrating sensitivity and specificity of $76.3 \%$ and $78.8 \%$ respectively using a cutoff score of 7 or higher to predict histological appendicitis. Kalan's study was limited to 11 children, all of which had modified Alvarado Scores $>=7$ and corresponding appendicitis. Obviously these numbers are too small to draw any conclusions (Macklin, Radcliffe, Merei, \& Stringer, 1997)(Kalan 1994).

Sooriakumaran et al further modified the score by decreasing the value of leukocytosis, to make a total score of 8 . This score was then compared to clinical assessment by Emergency Physicians, and found wanting. However, one must be cautious, as only 3 children were included (!), and, due to the change in total score, the threshold value was tested at 5 (Sooriakumaran, Lovell, \& Brown, 2005).

Significant changes to the Alvarado Score were suggested by Impellizzeri et al. who studied 156 children aged 2-17 years, replacing anorexia with an elevated fibrinogen level $(>400 \mathrm{mg} / \mathrm{dL})$, changing migration of pain to length of pain (although not defined), combining RLQ pain and rebound into one criteria, and decreasing the temperature cutoff to $37 \mathrm{C}$. Of note, the diagnosis of appendicitis was made on surgical report, not pathologic diagnosis. The authors suggest the above modifications would have decreased admission rates by $15 \%$ (Impellizzeri et al., 2002).

\subsection{The Pediatric Appendicitis Score (Samuel Score)}

Madan Samuel introduced the Pediatric Appendicitis Score (PAS) in 2002. A theoretical advantage to the PAS exists for 2 reason; 1) data was prospectively collected, and 2) the score was specifically derived in a population of children (aged $4-15$ years). The PAS has been subject to multiple subsequent validation and comparison studies.

Evaluating 1170 children with suspected appendicitis, Samuel compared historical, clinical and laboratory features in children with appendicitis $(n=734)$ and those without appendicitis $(n=436)$. Using stepwise multiple linear regression, 8 variables were included in a diagnostic model out of 10 points, with greater weight attributed to RLQ pain and maneuvers eliciting rebound tenderness (cough/percussion). Diagnostic criteria for the PAS are shown in Table 3. Samuel concludes that a score of 6 or greater shows a high probability of acute appendicitis.(Samuel, 2002) 
Unlike the Alvarado Score, there have been no attempts to modify the PAS. However, multiple studies have sought to prove its validity (Summary provided in Table 5). Two very high quality prospective trials have recently been completed. Goldman et al expanded the original age group by including 849 children aged 1 to 17 years, 123 of whom had histological appendicitis. Sensitivity and Specificity were $72 \%$ and $94 \%$ respectively. The Receiver Operating Curve (ROC) demonstrated high sensitivity with an Area Under the Curve (AUC) of 0.948. Goldman suggest increasing the threshold score to 7, and which would give a negative appendectomy rate of $4 \%$.(Goldman et al., 2008)

A similar study was published by Bhatt et al in 2009. Of the 246 children included in the study, 95 had surgical intervention. Using the standard PAS threshold of 6, the authors demonstrated a high sensitivity (93\%), but only a moderate specificity (69\%). Bhatt found an AUC that was slightly less in the study by Goldman at 0.895 . In this study population, the negative appendectomy rate would have approached $38 \%$. The authors concluded that a single threshold point would not be clinically relevant, but rather the PAS was useful in risk stratification into 3 groups; a) safe to discharge, b) requires further investigation through DI studies or c) requires direct surgical consultation. (Bhatt, Joseph, Ducharme, Dougherty, \& McGillivray, 2009)

A retrospective study by Goulder et al analyzed 56 children aged 4 to 15 years found less favorable results. Sensitivity remained high at $87 \%$, but specificity was significantly lower than the previously described studies at $59 \%$. Surgical intervention based on a threshold of 6 would have resulted in a negative appendectomy rate of $17 \%$ (Goulder \& Simpson, 2008).

Interestingly, a recent publication by Shera et al compared the Alvarado Score to what they considered a new modified score by replacing RLQ rebound tenderness with RLQ cough/percussion/hopping tenderness and weighing this element higher in value (2) while demoting leukocytosis to a value of 1 . This "new" modified score, however, seems to have the exact criteria of the PAS (Samuel combined cough/percussion tenderness with hopping tenderness because of good correlation and also promoted this elements value), and therefore could be considered in the PAS group (Shera, Nizami, Malik, Naikoo, \& Wani, 2010).

\subsection{Comparison of the Alvarado Score and the Pediatric Appendicitis Score}

Upon reviewing Table 3 one will notice the similarities between the Alvarado Score and the PAS. However, several differences exist between the two. These include the following:

1. The Alvarado Score was derived in a mixed pediatric/adult population (aged $4-80$ years) and subsequently validated in children. The PAS was derived in children (aged 4 -15 years).

2. The Alvarado Score was derived retrospectively and subsequently validated both retrospectively and prospectively. The PAS was derived prospectively and has been validated as such.

3. The Alvarado Score specifically defined elevated temperature as $\geq 37.3 \mathrm{C}$, while the PAS does not define pyrexia.

4. The Alvarado Score specifically defined neutrophilia as $>75 \%$, while the PAS does not define neutrophilia (similarly most subsequent studies utilize $>75 \%$ ).

5. The weighted criteria differ. Alvarado emphases leukocytosis, while Samuel places higher value on rebound tenderness.

Given the above differences, can one choose which score is better? Three well-designed prospective studies have performed head-to-head comparison of the Alvarado Score and the PAS. 
Schneider et al enrolled 755 children aged 3 to 21 years who were evaluated by their surgical team for suspected appendicitis. Alvarado Scores and PAS were calculated on 588 participants with complete data. Overall, the PAS was more sensitive (82\% vs. $72 \%)$ while the Alvarado Score was more specific ( $81 \%$ vs. $65 \%)$ in this population. Negative- and Positive- Predictive values were similar between groups ( 85 vs. $88 \%$ and 65 vs. $54 \%$ for Alvarado vs. PAS respectively). However, the Alvarado Score had a better Positive Likelihood ratio (3.8 vs. 2.4). ROC curves were similar between the two scores. Unfortunately, this study included patients up to 21 years of age, which may have improved the diagnostic accuracy of the score in this population, though the number of patients over 17 years was not large. Interestingly, the Positive Predictive Value of the Alvarado Score in children $<10$ years was diminished (65\% vs. $58 \%$ ) (Schneider, A. Kharbanda, \& R. Bachur, 2007).

\begin{tabular}{|c|c|c|c|c|c|c|c|c|c|c|c|c|c|c|}
\hline Study & Year & Population & Ages & Design & $\mathrm{T}+$ & F+ & F- & T- & Sens & Spec & PPV & NPV & Acc & Notes \\
\hline Samuel & 2002 & $\begin{array}{l}1170 \text { suspected } \\
\text { appendicitis }\end{array}$ & $\begin{array}{l}4 \text { to } 15 \\
\text { years }\end{array}$ & Prospective & 734 & 33 & 0 & 403 & $100 \%$ & $92 \%$ & $96 \%$ & $100 \%$ & $97 \%$ & $\begin{array}{l}\text { Derivation } \\
\text { Study }\end{array}$ \\
\hline Schneider & 2007 & $\begin{array}{l}821 \text { suspected } \\
\text { appendicitis } \\
588 \text { included }\end{array}$ & \begin{tabular}{|l}
3 to 21 \\
years
\end{tabular} & Prospective & 162 & 136 & 35 & 255 & $82 \%$ & $65 \%$ & $54 \%$ & $88 \%$ & $71 \%$ & $\begin{array}{l}\text { Alvarado/PAS } \\
\text { comparison }\end{array}$ \\
\hline Goulder & 2008 & $\begin{array}{l}60 \text { suspected } \\
\text { appendicitis } \\
56 \text { included }\end{array}$ & $\begin{array}{l}4 \text { to } 15 \\
\text { years }\end{array}$ & Retrospective & 34 & 7 & 5 & 10 & $87 \%$ & $59 \%$ & $83 \%$ & $67 \%$ & $79 \%$ & \\
\hline Goldman & 2008 & $\begin{array}{l}1060 \text { abdo pain } \\
849 \text { included }\end{array}$ & $\begin{array}{l}1 \text { to } 17 \\
\text { years }\end{array}$ & Prospective & 89 & 44 & 34 & 682 & $72 \%$ & $94 \%$ & $67 \%$ & $95 \%$ & $91 \%$ & $\begin{array}{l}\text { Calculations } \\
\text { based on } \\
\text { threshold }=6\end{array}$ \\
\hline Bhatt & 2009 & 275 convenience & $\begin{array}{l}4 \text { to } 18 \\
\text { years }\end{array}$ & Prospective & 77 & 50 & 6 & 113 & $93 \%$ & $69 \%$ & $61 \%$ & $95 \%$ & $77 \%$ & \\
\hline Escriba & 2011 & $\begin{array}{l}112 \text { suspected } \\
\text { appendicitis } \\
99 \text { included }\end{array}$ & $\begin{array}{l}4 \text { to } 18 \\
\text { years }\end{array}$ & Prospective & ? & ? & ? & ? & $88 \%$ & $98 \%$ & $97 \%$ & $92 \%$ & ? & $\begin{array}{l}\text { Alvarado/PAS } \\
\text { comparison }\end{array}$ \\
\hline Adibe & 2011 & $\begin{array}{l}112 \text { suspected } \\
\text { appendicitis }\end{array}$ & $\begin{array}{l}1 \text { to } 18 \\
\text { years }\end{array}$ & Prospective & 56 & 4 & 27 & 25 & $67 \%$ & $86 \%$ & $93 \%$ & $48 \%$ & $72 \%$ & \\
\hline Mandeville & 2011 & $\begin{array}{l}487 \text { diagnosed } \\
\text { appendicitis } \\
287 \text { included }\end{array}$ & \begin{tabular}{|l}
4 to 16 \\
years
\end{tabular} & Prospective & ? & ? & ? & ? & $88 \%$ & $50 \%$ & $67 \%$ & $79 \%$ & ? & $\begin{array}{l}\text { Alvarado/PAS } \\
\text { comparison } \\
\text { In Press }\end{array}$ \\
\hline
\end{tabular}

T+ True Positive, F+ False Positive, F- False Negative, T- True Negative, Sens Sensitivity,

Spec Specificity, PPV Positive Predictive Value, NPV Negative Predictive Value, Acc Accuracy, ? data not provided, N/A not applicable

Table 5. Summary of Studies Evaluating the Pediatric Appendicitis Score

More recently, Escriba et al evaluated 112 children aged 4 - 18 years, with 99 meeting the inclusion criteria. The authors published sensitivity and specificity for all cut-off values for both the Alvarado and the PAS, and favored using a value of 6-points for both tests (the Alvarado Score most commonly uses 7). In keeping with the traditional threshold values, 
the Alvarado Score had a sensitivity and specificity of $74 \%$ and $98 \%$; respective values for the PAS were $88 \%$ and $98 \%$. ROC curves for both Scores were similar (0.96 vs. 0.97) (Escribá, Gamell, Fernández, Quintillá, \& Cubells, 2011).

Using a slightly different approach, Mandeville enrolled 287 of 487 children aged 4 to 16 years with a clinical diagnosis of appendicitis in whom 155 had pathologically proven appendicitis. Similar to Schneider's results, the PAS was more sensitive (88\% vs. $76 \%$ ) while the Alvarado Score was more specific ( $72 \%$ vs. $50 \%)$. ROC curves were once again similar, yet somewhat lower than the two studies described above (PAS - 0.78, Alvarado - 0.78). When stratified by sex, both Scores had slightly improved sensitivities in boys (Mandeville, Pottker, \& Bulloch, 2010). The authors of these three prospective comparison studies concluded that there was insufficient evidence to favor one CSS over the other. Caution was stressed, suggesting that neither score was sensitive nor specific enough to be used as a stand-alone diagnostic test; further investigations such as Computed Tomography (CT) or Ultrasonography (US) were encouraged to complete the evaluation for intermediate-risk children.

The Alvarado Score and the PAS both make use of several key features of CSSs. The criteria are easy to elicit, each criteria is dichotomous (Yes/No), and the Score is easy to calculate. Overall, the PAS appears to be a more sensitive tool, while the Alvarado Score is more specific.

\subsection{The Low Risk for Appendicitis Score (Kharbanda)}

Increased ED wait times, hospital over-crowding and concerns related to radiation exposure from imaging studies have put pressure on clinicians to quickly and accurately decide which children with abdominal pain should be admitted and observed or discharged without a CT evaluation. Kharbanda et al derived and validated a score to do just that; identify children at low risk for appendicitis.

Kharbana et al prospectively enrolled 767 children aged 3 to 18 years with suspected appendicitis who were evaluated by a surgeon. Of these 767, 601 were included (425 derivation set, 176 validation set). Using logistic regression 6 weighted predictors of appendicitis were determined for a total score of 14. (Table 6) Children with a score of $<=5$ were highly unlikely to have appendicitis (sensitivity 99\%, NPV 98\%, NLR 0.032 during derivation, $96 \%, 96 \%$ and 0.102 for validation set)

\begin{tabular}{|l|l|}
\hline Diagnostic Criteria & Value \\
\hline Absolute Neutrophil Count $>6.75$ & 6 \\
Rebound pain or pain with percussion & 2 \\
Unable to walk, or walks with a limp & 1 \\
Nausea & 2 \\
History of migration of pain to RLQ & 1 \\
History of focal RLQ pain & 2 \\
\hline Total & $\mathbf{1 4}$ \\
\hline
\end{tabular}

Table 6. Diagnostic Criteria of Kharbanda's Low Risk Score 
In addition to creating the Low Risk Score, the Kharbanda study was novel in that it created a low risk decision tree using recursive partitioning. During derivation, the rule was perfectly sensitive, with a NPV of $98 \%$ and a NLR of 0 . Validation demonstrated a sensitivity of $98 \%$, NPV of $98 \%$ and NLR of 0.058 . The Low Risk decision tree in shown in Figure 1 (A. B. Kharbanda, Taylor, Fishman, \& R. G. Bachur, 2005).

Practically speaking, Kharbanda's Low Risk Score helps to answer the age old question "Can I safely send this child home?"

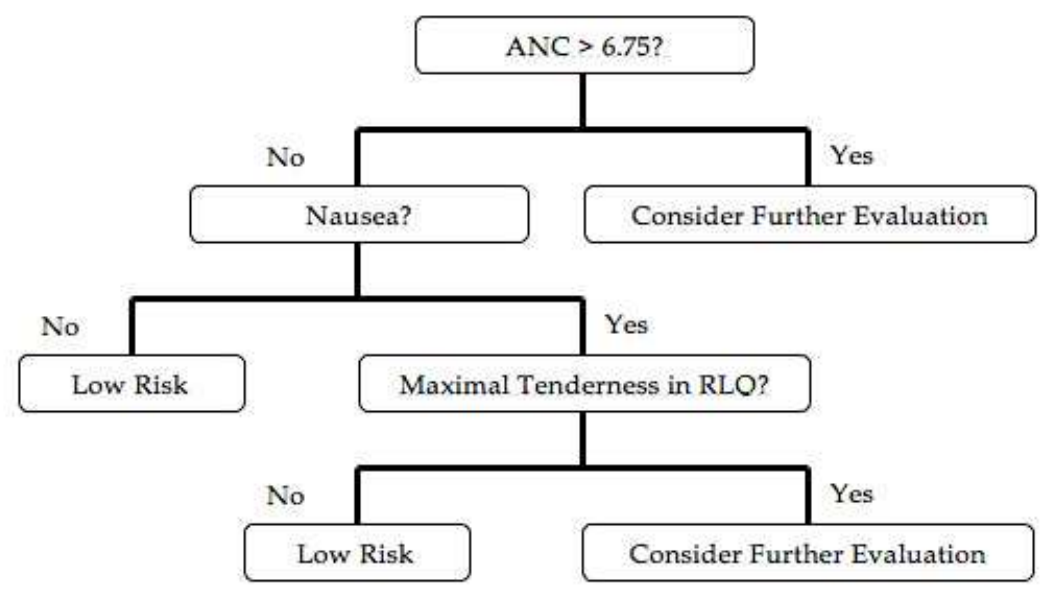

ANC - Absolute Neutrophil Count. RLQ - Right Lower Quadrant

Fig. 1. Decision Tree for identifying children at Low Risk for Appendicitis (Kharbanda)

\subsection{The Lintula Score}

The Lintula Score relies on clinical data alone. There are no laboratory results required. Using a nice 2-phased approach, Lintula et al first prospectively evaluated 35 clinical variables to derive a score in 127 children aged 4 to 15 years (Score criteria are found in Table 7). Subsequent prospective validation of the score was performed on a similar sample of 109 children. The Lintula Score has a maximum value of 32. A high risk threshold was established at $>=21$, while low risk was $<=15$ (Lintula, Pesonen, Kokki, Vanamo, \& Eskelinen, 2005).

Four years later, Lintula tested the score in a prospective randomized parallel design. Children aged 4 to 15 years randomized to assessment by score had surgical intervention based on the score result while intervention for those randomized to "no-score" was based on overall clinical and laboratory assessments by the surgeon. Assessments were made at three-hour intervals until a decision to operate or discharge home was established. Of note, imaging studies were not used in either group. Use of the Lintula Score resulted in a significantly higher accuracy ( $92 \%$ vs. $80 \%$ ) and a lower rate of negative appendectomies. The 2 groups showed no significant difference in sensitivity, however specificity was improved in the Lintula Score group (88\% vs. 67\%) (Lintula, Kokki, Kettunen, \& Eskelinen, 2009). 


\begin{tabular}{|l|l|l|}
\hline Diagnostic Criteria & Response & Value \\
\hline Gender & Male & 2 \\
& Female & 0 \\
\hline Intensity of Pain & Severe & 2 \\
& Mild to moderate & 0 \\
\hline Relocation of Pain & Yes & 4 \\
& No & 0 \\
\hline Vomiting & Yes & 2 \\
& No & 0 \\
\hline Pain in the RLQ & Yes & 4 \\
& No & 0 \\
\hline Fever $\geq 37.5$ & Yes & 3 \\
& No & 0 \\
\hline Guarding & Yes & 4 \\
& No & 0 \\
\hline Bowel Sounds & Absent, tinkling, high-pitched & 4 \\
& Normal & 0 \\
\hline Rebound Tenderness & Yes & 7 \\
& No & 0 \\
\hline Total Score & & 32 \\
\hline
\end{tabular}

Table 7. Diagnostic Criteria for the Lintula Score

\subsection{The Eskelinen Score}

The Eskelinen Score is relatively complex to perform, (requiring factor multiplication) and was originally designed for use within a computer program. Table 8 details the criteria and design.

Zielke et al compared the Eskelinen and Ohmann Scores using a pooled database of a total of 5 prospective studies. 2359 patients aged 0 to 95 years with suspected appendicitis were analyzed, of which 2209 were included. 845 of these underwent a laparotomy, with histological diagnosis confirmed in 662. Sensitivity, Specificity, PPV, NPV and accuracy were $70 \%, 92 \%, 73 \%, 90 \%$ and $87 \%$ (Zielke 2001).

\begin{tabular}{|l|l|l|l|}
\hline Diagnostic Criteria & Presence/Absence & Multiplication Factor & Final Value \\
\hline Tenderness in RLQ & Yes -2, No -1 & 11.41 & \\
\hline Rigidity & Yes -2, No -1 & 6.62 & \\
\hline WBC $>10000$ & Yes -2, No -1 & 5.88 & \\
\hline Rebound Tenderness & Yes -2, No -1 & 4.25 & \\
\hline Pain in RLQ at Presentation & Yes -2, No -1 & 3.51 & \\
\hline Duration of pain $>48$ hours & Yes -2, No -1 & 2.13 & $\mathbf{6 6 7 . 6}$ \\
\hline & & Total Score: \\
\hline
\end{tabular}

Table 8. Factorial Multiplication Design of the Eskelinen Score

Taking advantage of the complete pooled database of Zielke (2359 patients), Sitter et al used a higher predetermined threshold score of 55 to determine a sensitivity, specificity, PPV, NPV and accuracy of $79 \%, 85 \%, 68 \%, 91 \%$ and $84 \%$. The corresponding AUC of the ROC 
was 0.91 . The authors further calculated these statistical variables using thresholds ranging from 50 to 60, and determined 57 to be the most favorable in their population. (Sitter, Hoffmann, Hassan, \& Zielke, 2004)

\subsection{The Fenyo-Lindberg Score}

This score appears to be one of the most complex, incorporating criteria with multiple levels of response that both add to and subtract from the total score. (Diagnostic Criteria found in Table 9) In 1987, Fenyo prospectively evaluated 259 adult patients with suspected appendicitis. The resulting score was further validated in 830 patients, of which 256 had proven appendicitis. Sensitivity, Specificity, PPV and NPV were 90\%, 91\%, 83\% and 95\% respectively. (Fenyo 1987)

Fenyo and Lindberg prospectively validated their score in 1167 patients with suspected appendicitis. Of these, 392 had histologically proven appendicitis. Using the standard threshold score of -2 to predict appendicitis, the sensitivity was $73 \%$ and specificity was $87 \%$, notably less than in the original study. Of note, this study made use of 2 different settings, a district and a university hospital. 30\% of the patients included from the University hospital were children (age unknown) (Fenyö, Lindberg, Blind, Enochsson, \& Oberg, 1997).

\begin{tabular}{|l|l|l|}
\hline Diagnostic Criteria & Response & Value \\
\hline Sex & Male & +8 \\
& Female & -8 \\
\hline WBC & $\geq 14$ & +10 \\
& $9.0-13.9$ & +2 \\
& $\leq 8.9$ & -15 \\
\hline Duration of Pain (hours) & $<24$ & +3 \\
& $24-48$ & 0 \\
& $>48$ & -12 \\
\hline Progression of Pain & Yes & +3 \\
& No & -4 \\
\hline Relocation of pain & Yes & +7 \\
& No & -9 \\
\hline Vomiting & Yes & +7 \\
& No & -5 \\
\hline Aggravation by coughing & Yes & +4 \\
& No & -11 \\
\hline Rebound Tenderness & Yes & +5 \\
& No & -10 \\
\hline Rigidity & Yes & +15 \\
& No & -4 \\
\hline Tenderness outside RLQ & Yes & -6 \\
& No & +4 \\
\hline Constant & & -10 \\
\hline
\end{tabular}

Table 9. Diagnostic Criteria of the Fenyo-Lindberg Score 
Once again, modification to a CSS was studied. The following changes were made by Dado et al: a) increased WBC cut-off values $(<12,12-20,>20), b)$ altered values of migratory pain $($ Yes +4 , No -11), c) insertion of elevated temperature $>37.5$ C (Yes +7 , No -9), and d) removal of aggravation by coughing. 197 children aged 2 to 17 years were retrospectively stratified into 3 risk groups using the modified Lindberg Score. Sensitivity and Specificity were $86 \%$ and $87 \%$, with an excellent PPV of $96 \%$, but only a modest NPV at $69 \%$ (Dado et al., 2000).

\subsection{The Ohmann Score}

In 1999, Ohmann prospectively validated his own score in a multi-centre, multi-phase trial (Diagnostic Criteria are found in Table 10). Subjects evaluated during phase $1(n=870)$ received surgical intervention based on surgeon assessment, while those in phase $2(n=614)$ received computer-assisted diagnostic support using the Ohmann Score. Children less then 6 were excluded from the study, overall pediatric numbers were not published. The authors found a statistically significant improvement in specificity, PPV and accuracy in the phase 2 Score group, along with a decrease in the number of delayed diagnoses (defined as appendectomy on the second day after admission or later) (Ohmann 1999).

Several studies have evaluated the Ohmann Score. In a large study of 2359 subjects (age 0 95 years) Zielke compared the score to clinical assessments. Overall accuracy using the Ohmann Score was found to be better than junior surgical staff, with a sensitivity, specificity, PPV, NPV and accuracy of $63 \%, 93 \%, 77 \%, 86 \%$ and $84 \%$. However, it was not found to be better than senior surgical staff assessments. (Zielke et al., 1999) Data from this population was further used to compare CSS's, Ohmann Scores, Eskelinen Scores and Ultrasonography with similar statistical results. (Zielke 2001)

\begin{tabular}{|l|l|}
\hline Diagnostic Criteria & Value \\
\hline Tenderness in the RLQ & 4.5 \\
Rebound Tenderness & 2.5 \\
No Micturation Difficulties & 2.0 \\
Steady Pain & 2.0 \\
WBC > 10 & 1.5 \\
Age < 50 & 1.5 \\
Relocation of pain to RLQ & 1.0 \\
Rigidity & 1.0 \\
\hline Maximum Total Score & $\mathbf{1 6}$ \\
\hline
\end{tabular}

Table 10. Diagnostic Criteria of the Ohmann Score

\subsection{The Christian Score}

Probably the simplest of the group, the Christian Score uses a mere 5 criteria (Diagnostic Criteria are found in Table 11). The case group of 58 subjects with suspected appendectomy had surgical intervention if $>=4$ criteria were met. Fifty-nine appendectomy controls had 
intervention based solely on surgical staff assessment. Ages ranged from 7 to 56 years. The negative appendectomy rate was significantly less in the Score group than that of the controls $(6.5 \%$ vs. $17 \%)$. This is a rather simple score, which unfortunately does not to appear to have been validated or assessed in a pediatric specific population, but probably should be (Christian 1992).

\begin{tabular}{|l|}
\hline Abdominal pain on history, occurring within 48 hours of presentation \\
\hline Vomiting - one or more episode \\
\hline RLQ tenderness on examination \\
\hline Low grade fever - defined as $<=38.8 \mathrm{C}$ \\
\hline Polymorphonuclear leukocytosis - define as WBC $>10000$ AND neutrophils $>75 \%$ \\
\hline
\end{tabular}

Table 11. Diagnostic Criteria for the Christian Score

\subsection{The RIPASA Score}

What is probably the newest member to the group of appendicitis scores is the RIPASA Score, named after its hospital of origin in Brunei. A mixed population of 400 adults and children who had an appendectomy were retrospectively identified, the records of 312 were used to derive the score. Individual criteria were weighted $(0.5,1,2)$ based on probabilities and a panel of staff surgeons. The resulting maximal RIPASA score is 16 (diagnostic criteria are found in Table 12); a threshold of 7.5 proving a sensitivity of $88 \%$ and specificity of $67 \%$ PPV and NPV were $93 \%$ and $53 \%$, while accuracy was $81 \%$. Using the score, an absolute reduction in negative appendectomies of $9 \%$ would have occurred. (Chong 2010)

\begin{tabular}{|l|l|}
\hline Diagnostic Criteria & Value \\
\hline Sex & $1.0-$ Male \\
& $0.5-$ Female \\
\hline Age & $1.0-<39.9$ years \\
& $0.5->40$ years \\
\hline RLQ pain & 0.5 \\
\hline Migration of RLQ pain & 0.5 \\
\hline Anorexia & 1.0 \\
\hline Nausea \& Vomiting & 1.0 \\
\hline Duration of Symptoms & $1.0-<48$ hours \\
& $0.5->48$ hours \\
\hline RLQ tenderness & 1.0 \\
\hline RLQ guarding & 2.0 \\
\hline Rebound tenderness & 1.0 \\
\hline Rovsig Sign & 2.0 \\
\hline Fever (not defined) & 1.0 \\
\hline Raised WBC (not defined) & 1.0 \\
\hline Negative Urinalysis (no blood, neutrophils, bacteria) & 1.0 \\
\hline Foreign National registration Identity Card & 1.0 \\
\hline
\end{tabular}

Table 12. Diagnostic Criteria for RIPASA Score 
Chong et al continued to evaluate their new score by prospectively enrolling 200 adults and children in a comparison of the RIPASA and Alvarado Scores. In this group of patients, the RIPASA was statistically superior to the Alvarado Score in Sensitivity (98\% vs. 68\%), NPV (97\% vs. $71 \%$ ) and accuracy (92\% vs. $87 \%)$. Specificity, PPV and negative appendectomy rates were similar between the 2 scores. (Chong 2011)

\subsection{Other Scores}

Several other CSSs have been developed for patients with suspected appendicitis, but do not appear to have been formally evaluated in children and as a result are not further discussed in this chapter. Some of these include the Teicher Score, Arnbjornsson Score, Izbicki Score, and DeDombal Score.

\section{Clinical Scoring Systems in practice: Experience of the Alberta Children's Hospital Pediatric Appendicitis Pathway}

The real test of a CSS is whether it works in practice. Here I report our experience at the Alberta Children's Hospital (ACH) during a Quality Improvement process from 2006-2011. The Alberta Children's Hospital is a tertiary referral centre for children aged 0 - 18 years, serving a population of approximately 1.8 million in southern Alberta, western Saskatchewan and eastern British Columbia, the 3 western-most provinces of Canada. The Pediatric Emergency Department (PED) at ACH has an annual census of approximately 60 000 visits, and the surgical staff perform approximately 350 acute appendectomies each year.

Following several highly publicized adverse outcomes surrounding appendicitis in both children and adults in the former Calgary Health Region (now Alberta Health Services Calgary and Area), a formal safety review was conducted. Early diagnosis and standardization of care were determined to be of utmost importance. As a result, Clinical Pathways were developed for both adults and children.

Early diagnosis remains a significant challenge for the pediatrician. After reviewing the literature related to CSSs, the ACH Pediatric Appendicitis Committee agreed to incorporate a score into the pathway development to assist in standardization of assessment, investigation and inter-disciplinary communication. The Alvarado Score and PAS were felt to have similar qualities and to be the most thoroughly evaluated of the CSSs in children with acceptable performance for risk stratification. Since a number of staff groups are employed in both pediatric and adult hospital settings one consistent CSS was felt to be optimal. The Alvarado Score was incorporated into both the adult and pediatric Appendicitis Pathways for the region.

The Pediatric Appendicitis Pathway (Figure 2) uses the Alvarado Score in 2 different ways; the first is a novel departmental flow advancement through a screening tool that initiates Advanced Nursing Directives (ANDs); the second, is a risk stratification tool for physician decision making. Since ED assessment and management are a team effort, we felt it was vital for both nursing and medical staff to use an assessment tool with common features.

\subsection{Incorporating Clinical Scoring Systems into Advanced Nursing Directives}

Advanced Nursing Directives are used in the ACH PED to improve patient flow and reduce waiting times. ANDs are not simple nursing protocols for administering antipyretics for children with fever or non-steroidal anti-inflammatory drugs for musculo-skeletal pain. Nor 
are they meant to formally diagnose disease. Rather they are a recognition that skilled nurses are able to identify certain common disease processes (in this case appendicitis), that some of these disease presentations have common investigations and/or management processes, and that empowering pediatric emergency nurses in the frontline can expedite patient care. The purpose of an AND, therefore, is 1) to assist pediatric emergency nurses in identifying children who would likely need further investigation and (2) to empower pediatric emergency nurses to initiate investigations and management before pediatric emergency physician assessment (deForest \& Thompson, 2010). (Thompson 2010a)

A number of ED practices, such as initiating intravenous access and fluid management, are commonly performed by nurses caring for adults but are less widely performed in children. Pediatric centres rightly try to limit potentially painful procedures unless they are absolutely required and our AND aims to do precisely this. The important components of any AND include standardized assessment measures using set criteria, a defined care plan if criteria are met, and the option to seek assistance when necessary. Validated CSSs are ideal for integration into an AND.

It must be recognized that different clinical settings may be more appropriate for the use of ANDs. For some health care centres, implementing ANDs into departmental flow may stretch beyond normal nursing practice. For others, it may simply be a matter of formally documenting a process already in place.

The Alvarado Score utilizes both clinical and laboratory variables but at the initial assessment triage of a child with abdominal pain laboratory results are rarely available. Our AND (Figure 3) uses a modification of the original score, leaving out laboratory criteria, and increasing the cutoff value of elevated temperature from $37.3 \mathrm{C}$ to $38.0 \mathrm{C}$ (as a fever is defined as temperature $>38 \mathrm{C}$ in our department). The remaining historical and clinical variables are evaluated by the nursing staff and recorded as a dichotomous variable, either Yes or No. If overall AND criteria are met, the nursing staff are empowered to initiate intravenous access, obtain blood and urine samples for laboratory assessment and give a bolus of crystalloid fluid. These processes occur prior to physician assessment. The objectives of the AND are to identify children with suspected appendicitis earlier in their health care visit, to decrease the time to obtain laboratory results, to identify potential confounding diagnoses early on (i.e. urinary tract infection, pregnancy) and to prepare the child for potential diagnostic imaging.

Preliminary data demonstrates accuracy of our nurses in predicting appendectomy using the AND is similar to the previously published data from the Alvarado Score studies discussed above (Sensitivity 72\%, Specificity 72\%, NPV 91\%, PPV 40\%, accuracy 72\%. (Thompson 2010b)

\subsection{Incorporating the Alvarado Score for medical decision making in the ACH PED}

It is well recognized that some children presenting to the ED clearly require surgery for acute appendicitis. However, over the last 2 decades, there has become increased reliance on Diagnostic Imaging modalities (DI) to confirm or rule out appendicitis and potentially provide alternate diagnoses (particularly in post-menarchal girls). Given the availability of DI including Ultrasonography (U/S) and Computed Tomography (CT), and the relatively high sensitivity and specificity of these tests, they are often requested by the surgical team in order to improve diagnostic accuracy and decrease the rate of negative appendectomy. However, given recent concerns related to radiation exposure in children (Brenner \& Hall, 2007), as well as overcrowding in many EDs and DI departments leading to delays in imaging acquisition, a more responsible approach to risk stratification is required. 


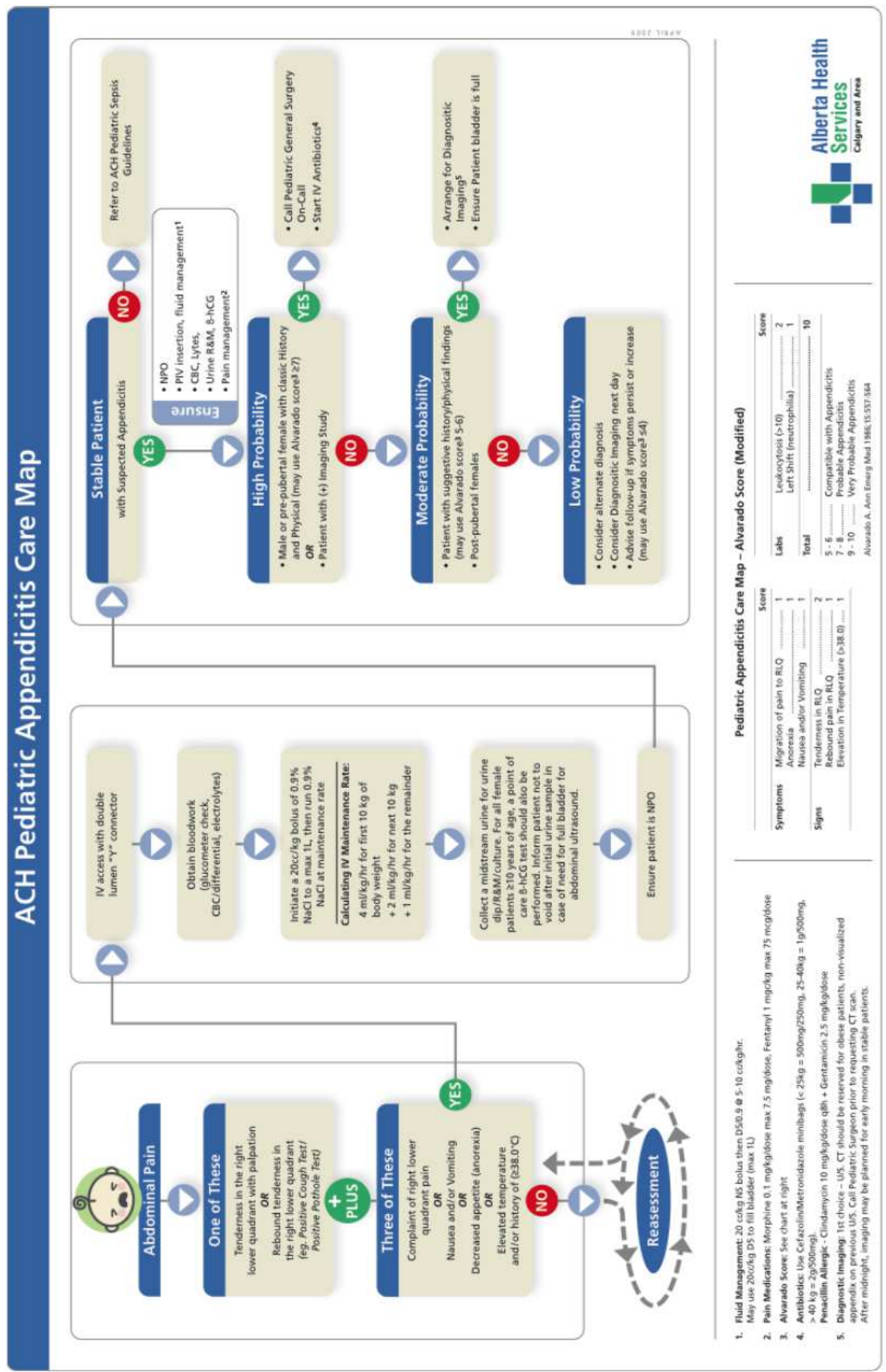

Fig. 2. The Alberta Children's Hospital Appendicits Pathway 
Patient Information Label

\section{Nursing Protocol for the Child with Suspected Appendicitis}

Purpose: For Emergency Nursing staff to initiate investigations and treatment for the patient presenting in the Emergency Department with signs and symptoms of ap pendicitis prior to an assessment by an Emergency Physician.

For this protocol to be initiated:

\begin{tabular}{|c|c|c|}
\hline The patient must have ONE of the following clinical signs: & YES & $\mathrm{NO}$ \\
\hline $\begin{array}{l}\text { - Any tenderness in the right lower quadrant with palpation by examiner } \\
\mathbf{O R}\end{array}$ & & $!$ \\
\hline
\end{tabular}

\begin{tabular}{|c|c|c|}
\hline The patient must also have 3 OR MORE of the following screening criteria: & YES & $\mathrm{NO}$ \\
\hline - Any complaint of right lower quadrant pain by patient & $!$ & $!$ \\
\hline - Nausea and/or vomiting & ! & ! \\
\hline - Decreased appetite (anorexia) & ! & $\vdots$ \\
\hline - Elevated temperature and/or history of $\left(" 38.0^{\circ} \mathrm{C}\right)$ & ! & ! \\
\hline
\end{tabular}

Does this patient meet the above clinical criteria? ！ YES ！ NO

If a patient meets the above screening criteria, an Emergency Depar tment Nurse is able to perform the following procedures prior to Emergency Department Physician assessment/orders:

- IV access with double lumen "Y" connector

- Obtain bloodwork (glucometer check, CBC/differential, electrolytes)

- Initiate a $20 \mathrm{cc} / \mathrm{kg}$ bolus of $0.9 \% \mathrm{NaCl}$ (maximum 1 litre), then run $0.9 \% \mathrm{NaCl}$ at maintenance rate:

\begin{tabular}{ll} 
Calculating IV Maintenance Rate: & Example Calculation for patient weighing 27kg: \\
\hline $4 \mathrm{ml} / \mathrm{kg} / \mathrm{hr}$ for first $10 \mathrm{~kg}$ of body weight & $4 \mathrm{mlx} 10 \mathrm{~kg}=40 \mathrm{ml} / \mathrm{kg} / \mathrm{hr}$ \\
$+2 \mathrm{ml} / \mathrm{kg} / \mathrm{hr}$ for next $10 \mathrm{~kg}$ & $+2 \mathrm{mlx} 10 \mathrm{~kg}=20 \mathrm{ml} / \mathrm{kg} / \mathrm{hr}$ \\
$+1 \mathrm{ml} / \mathrm{kg} / \mathrm{hr}$ for the remainder & $+1 \mathrm{mlx} 7 \mathrm{~kg}=7 \mathrm{ml} / \mathrm{kg} / \mathrm{hr}=67 \mathrm{ml} / \mathrm{kg} / \mathrm{hr}$ maintenance rate
\end{tabular}

- Collect a midstream urine for urine dip/R\&M, send for culture if urine dip is positive. For all female patients " 10 years of age, a point of care \#-HCG test should also be performed. Inform patient not to void after initial urine sample in case of need for full bladder for abdominal ultrasound.

- Ensure patient is NPO

A maximum of 2 IV attempts will be made prior to the Physician's assessment. The Nurse will communicate with the Charge Nurse to ensure that the patient is prioritized appropriately prior to initiation of this protocol.

Fig. 3. Alberta Children's Hospital Advanced Nursing Directive for children with suspected appendicitis

High risk patients (Alvarado Score $\geq 7$ ) are evaluated by the surgical team after consultation by the ED staff without the need for imaging. Similarly, children at low risk for appendicitis with an Alvarado Score of $\leq 4$, are evaluated by the ED staff for alternate diagnoses or managed with watchful waiting in the home setting, to return should the child's condition worsen. Those children at moderate risk for appendicitis (Alvarado 5-6) or those with high risk for alternate diagnoses (post-menarchal females) are most likely to benefit from imaging studies. 
Our post - implementation data has shown that over $40 \%$ of appendectomy patients went to the Operating Room (OR) without any imaging studies, a reflection of high risk stratification related to incorporating the Alvarado Score into our pathway. (Thompson 2010c)

\section{Implementation and measurement}

While it is well known that incorporating carefully developed CSSs into practice improves patient care and departmental processes, the optimal method of implementation is yet to be determined. Many local, national and international medical organizations have developed strategies related to implementation science and knowledge management/translation. Cognitive, social, motivational and organization factors all influence knowledge uptake and use (Gaddis, Greenwald, \& Huckson, 2007).

Realistically, it is difficult to achieve $100 \%$ uptake of CSSs. Careful planning, with input from all key stakeholders is vital. Introducing new system processes for the care of the child with suspected appendicitis has a multidisciplinary impact. It is highly advisable to solicit representative input from Emergency Medicine, Surgery, Nursing, Diagnostic Imaging, Infectious Disease, Anesthesia, Pharmacy as well as unit managers of Emergency Department, Operating Room, and clinical wards. In order to optimize the potential buy-in from these key stakeholders, departmental leaders would be wise to identify specific outcomes measures ("key wins") geared to each discipline that they will target, for example reduced ED and post-operative lengths of stay.

Donabedian identifies 3 quality measurement pillars. These include structural measures (factors that are present prior to a client visit), process measures (factors occurring during the client visit) and outcome measures (factors occurring after the client visit). Ideally, these outcomes are easily measurable, and within attainable reach (Donabedian, 1992)(Schiff \& Rucker, 2001).

The statistical Methods for measuring change related to implementation of CSSs are beyond the scope of this chapter. Interested readers are encouraged to review the literature on Quality Assessment and Measurement.

\section{Conclusions}

Due to the often-difficult task of the early identification of appendicitis in children, the development of CSSs has increased over the last 3 decades. While most clinicians caring for children with suspected appendicitis are well versed in regard to the Alvarado Score and the Pediatric Appendicitis Score, many other models have been developed. Overall, these scores have been shown to improve clinical and process outcomes including reduced negative appendectomy rates, reduced radiation exposure from unwarranted DI studies, and reduced missed diagnoses. However, one must remain optimistically cautious; to date these Scores have yet to demonstrate a sensitivity or specificity sufficient enough to recommend their use beyond a calculated risk stratification (low, moderate or high).

Even with the abundance of literature regarding CSSs related to appendicitis in children, the need for well-designed, prospective studies to further validate the scores, evaluate implementation strategies and assess impact provides ample opportunity for future research. Due to the vast number of CSSs and the significant variability in the quality and quantity of validation studies, implementing Clinical Scores into practice can be challenging for individual clinicians. Departmental leaders should therefore carefully consider incorporating CSSs into locally driven Evidence Based Clinical Algorithms. 


\section{Acknowledgments}

The author would like to acknowledge the significant contributions of Mr. Spencer Stevens, Information Services Assistant, Health Information Network Calgary/Alberta Children's Hospital Knowledge Centre and Ms. Luisa Steen, Administrative Assistant, Division of Pediatric Emergency Medicine, Alberta Children's Hospital.

\section{References}

Alvarado, A. (1986). A practical score for the early diagnosis of acute appendicitis Annals of Emergency Medicine, 15(5), 557-564.

Beattie, P., \& Nelson, R. (2006). Clinical prediction rules: what are they and what do they tell us The Australian journal of physiotherapy, 52(3), 157-163.

Bhatt, M., Joseph, L., Ducharme, F. M., Dougherty, G., \& McGillivray, D. (2009). Prospective validation of the pediatric appendicitis score in a Canadian pediatric emergency department Academic emergency medicine : official journal of the Society for Academic Emergency Medicine, 16(7), 591-596. doi:10.1111/j.1553-2712.2009.00445.x

Bond, G. R., Tully, S. B., Chan, L. S., \& Bradley, R. L. (1990). Use of the MANTRELS score in childhood appendicitis: a prospective study of 187 children with abdominal pain Annals of Emergency Medicine, 19(9), 1014-1018.

Brenner, D. J., \& Hall, E. J. (2007). Computed tomography--an increasing source of radiation exposure The New England journal of medicine, 357(22), 2277-2284. doi:10.1056/NEJMra072149

Chang, Y.-C., Ng, C.-J., Chen, Y.-C., Chen, J.-C., \& Yen, D. H. T. (2010). Practice variation in the management for nontraumatic pediatric patients in the ED The American Journal of Emergency Medicine, 28(3), 275-283. doi:10.1016/j.ajem.2008.11.021

Dado, G., Anania, G., Baccarani, U., Marcotti, E., Donini, A., Risaliti, A., Pasqualucci, A., et al. (2000). Application of a clinical score for the diagnosis of acute appendicitis in childhood: a retrospective analysis of 197 patients Journal of Pediatric Surgery, 35(9), 1320-1322. doi:10.1053/jpsu.2000.9316

deForest, E. K., \& Thompson, G. C. (2010). Implementation of an advanced nursing directive for suspected appendicitis to empower pediatric emergency nurses Journal of emergency nursing: JEN : official publication of the Emergency Department Nurses Association, 36(3), 277-281. doi:10.1016/j.jen.2010.02.015

Donabedian, A. (1992). Quality assurance. Structure, process and outcome Nursing standard (Royal College of Nursing (Great Britain) : 1987), 7(11 Suppl QA), 4-5.

Eitel, D. R., Rudkin, S. E., Malvehy, M. A., Killeen, J. P., \& Pines, J. M. (2010). Improving Service Quality by Understanding Emergency Department Flow: A White Paper and Position Statement Prepared For the American Academy of Emergency Medicine. The Journal of emergency medicine, 38(1), 70-79. Elsevier Inc. doi:10.1016/j.jemermed.2008.03.038

Escribá, A., Gamell, A. M., Fernández, Y., Quintillá, J. M., \& Cubells, C. L. (2011). Prospective validation of two systems of classification for the diagnosis of acute appendicitis Pediatric emergency care, 27(3), 165-169.

doi:10.1097/PEC.0b013e31820d6460 
Fenyö, G., Lindberg, G., Blind, P., Enochsson, L., \& Oberg, A. (1997). Diagnostic decision support in suspected acute appendicitis: validation of a simplified scoring system The European journal of surgery = Acta chirurgica, 163(11), 831-838.

Gaddis, G. M., Greenwald, P., \& Huckson, S. (2007). Toward improved implementation of evidence-based clinical algorithms: clinical practice guidelines, clinical decision rules, and clinical pathways Academic emergency medicine : official journal of the Society for Academic Emergency Medicine, 14(11), 1015-1022. doi:10.1197/j.aem.2007.07.010

Goldman, R. D., Carter, S., Stephens, D., Antoon, R., Mounstephen, W., \& Langer, J. C. (2008). Prospective validation of the pediatric appendicitis score. The Journal of Pediatrics, 153(2), 278-282. doi:10.1016/j.jpeds.2008.01.033

Goldman, R. D., Scolnik, D., Chauvin-Kimoff, L., Farion, K. J., Ali, S., Lynch, T., Gouin, S., et al. (2009). Practice variations in the treatment of febrile infants among pediatric emergency physicians PEDIATRICS, 124(2), 439-445. doi:10.1542/peds.2007-3736

Goulder, F., \& Simpson, T. (2008). Pediatric appendicitis score: A retrospective analysis Journal of Indian Association of Pediatric Surgeons, 13(4), 125-127. doi:10.4103/09719261.44761

Hsiao, K.-H., Lin, L.-H., \& Chen, D.-F. (2005). Application of the MANTRELS scoring system in the diagnosis of acute appendicitis in children Acta paediatrica Taiwanica = Taiwan er ke yi xue hui za zhi, 46(3), 128-131.

Impellizzeri, P., Centonze, A., Antonuccio, P., Turiaco, N., Cifalà, S., Basile, M., Argento, S., et al. (2002). Utility of a scoring system in the diagnosis of acute appendicitis in pediatric age. A retrospective study Minerva chirurgica, 57(3), 341-346.

Jain, S., Elon, L. K., Johnson, B. A., Frank, G., \& Deguzman, M. (2010). Physician practice variation in the pediatric emergency department and its impact on resource use and quality of care Pediatric emergency care, 26(12), 902-908. doi:10.1097/PEC.0b013e3181fe9108

Kharbanda, A. B., Taylor, G. A., Fishman, S. J., \& Bachur, R. G. (2005). A clinical decision rule to identify children at low risk for appendicitis PEDIATRICS, 116(3), 709-716. doi:10.1542/peds.2005-0094

Laupacis, A., Sekar, N., \& Stiell, I. G. (1997). Clinical prediction rules. A review and suggested modifications of methodological standards JAMA: The Journal of the American Medical Association, 277(6), 488-494.

Lintula, H., Kokki, H., Kettunen, R., \& Eskelinen, M. (2009). Appendicitis score for children with suspected appendicitis. A randomized clinical trial Langenbeck's Archives of Surgery, 394(6), 999-1004. doi:10.1007/s00423-008-0425-0

Lintula, H., Pesonen, E., Kokki, H., Vanamo, K., \& Eskelinen, M. (2005). A diagnostic score for children with suspected appendicitis Langenbeck's Archives of Surgery, 390(2), 164-170. doi:10.1007/s00423-005-0545-8

Macklin, C. P., Radcliffe, G. S., Merei, J. M., \& Stringer, M. D. (1997). A prospective evaluation of the modified Alvarado score for acute appendicitis in children Annals of the Royal College of Surgeons of England, 79(3), 203-205.

Mandeville, K., Pottker, T., \& Bulloch, B. (2010). Using appendicitis scores in the pediatric ED. American Journal of Emergency Medicine, 1-6. Elsevier B.V. doi:10.1016/j.ajem.2010.04.018 
McGinn, T. G., Guyatt, G. H., Wyer, P. C., Naylor, C. D., Stiell, I. G., \& Richardson, W. S. (2000). Users' guides to the medical literature: XXII: how to use articles about clinical decision rules. Evidence-Based Medicine Working Group JAMA: The Journal of the American Medical Association, 284(1), 79-84.

Ohmann, C., Yang, Q., \& Franke, C. (1995). Diagnostic scores for acute appendicitis. Abdominal Pain Study Group The European journal of surgery = Acta chirurgica, 161(4), 273-281.

Plint, A. C., Johnson, D. W., Wiebe, N., Bulloch, B., Pusic, M., Joubert, G., Pianosi, P., et al. (2004). Practice variation among pediatric emergency departments in the treatment of bronchiolitis Academic emergency medicine : official journal of the Society for Academic Emergency Medicine, 11(4), 353-360.

Rezak, A., Abbas, H. M. A., Ajemian, M. S., Dudrick, S. J., \& Kwasnik, E. M. (2011). Decreased use of computed tomography with a modified clinical scoring system in diagnosis of pediatric acute appendicitis Archives of surgery (Chicago, Ill : 1960), 146(1), 64-67. doi:10.1001/archsurg.2010.297

Richer, L. P., Laycock, K., Millar, K., Fitzpatrick, E., Khangura, S., Bhatt, M., Guimont, C., et al. (2010). Treatment of children with migraine in emergency departments: national practice variation study PEDIATRICS, 126(1), e150-5. doi:10.1542/peds.2009-2337

Rivers, E., Nguyen, B., Havstad, S., Ressler, J., Muzzin, A., Knoblich, B., Peterson, E., et al. (2001). Early goal-directed therapy in the treatment of severe sepsis and septic shock. The New England journal of medicine, 345(19), 1368-1377.

Samuel, M. (2002). Pediatric appendicitis score Journal of Pediatric Surgery, 37(6), 877-881.

Schiff, G. D., \& Rucker, T. D. (2001). Beyond structure-process-outcome: Donabedian's seven pillars and eleven buttresses of quality The Joint Commission journal on quality improvement, 27(3), 169-174.

Schneider, C., Kharbanda, A., \& Bachur, R. (2007). Evaluating appendicitis scoring systems using a prospective pediatric cohort Annals of Emergency Medicine, 49(6), 778-84, 784.e1. doi:10.1016/j.annemergmed.2006.12.016

Shera, A. H., Nizami, F. A., Malik, A. A., Naikoo, Z. A., \& Wani, M. A. (2010). Clinical Scoring System for Diagnosis of Acute Appendicitis in Children. Indian journal of pediatrics, 78(3), 287-290. doi:10.1007/s12098-010-0285-9

Shreef, K., Waly, A., Abd-Elrahman, S., \& Abd Elhafez, M. (2010). Alvarado score as an admission criterion in children with pain in right iliac fossa. African Journal of Paediatric Surgery, 7(3), 163. doi:10.4103/0189-6725.70417

Sitter, H., Hoffmann, S., Hassan, I., \& Zielke, A. (2004). Diagnostic score in appendicitis. Validation of a diagnostic score (Eskelinen score) in patients in whom acute appendicitis is suspected Langenbeck's Archives of Surgery, 389(3), 213-218. doi:10.1007/s00423-003-0436-9

Sooriakumaran, P., Lovell, D., \& Brown, R. (2005). A comparison of clinical judgment vs the modified Alvarado score in acute appendicitis International journal of surgery (London, England), 3(1), 49-52. doi:10.1016/j.ijsu.2005.03.009

Stiell, I. (2001). Canadian CT head rule study for patients with minor head injury: methodology for phase II (validation and economic analysis). Annals of Emergency Medicine, 38(3), 317-322. doi:10.1067/mem.2001.116795 
Stiell, I. G., Greenberg, G. H., McKnight, R. D., Nair, R. C., McDowell, I., \& Worthington, J. R. (1992). A study to develop clinical decision rules for the use of radiography in acute ankle injuries Annals of Emergency Medicine, 21(4), 384-390.

Stiell, I. G., Greenberg, G. H., McKnight, R. D., Nair, R. C., McDowell, I., Reardon, M., Stewart, J. P., et al. (1993). Decision rules for the use of radiography in acute ankle injuries. Refinement and prospective validation JAMA: The Journal of the American Medical Association, 269(9), 1127-1132.

Stiell, I. G., Wells, G. A., Vandemheen, K. L., Clement, C. M., Lesiuk, H., de Maio, V. J., Laupacis, A., et al. (2001). The Canadian C-spine rule for radiography in alert and stable trauma patients. JAMA: The Journal of the American Medical Association, 286(15), 1841-1848.

Thompson GC, deForest EK, Eccles R, Ensuring Diagnostic Accuracy in Pediatric Emergency Medicine, Clinical Pediatric Emergency Medicine 2011 12(2):121.

Thompson GC, Stang A, deForest E, Eccles R. Can Pediatric Emergency Nurses Use a Modified Alvarado Score to Accurately Predict Appendecomy? Academic Emergency Medicine 17(5):s118

Thompson GC, Stang A, deForest E, Boag G, Eccles R. Utilization of Diagnostic Imaging after Implementation of a Clinical Pathway for Suspected Pediatric Appendicitis Paediatrics and Child Health 2010 15suppl:31A.

Zielke, A., Sitter, H., Rampp, T. A., Schäfer, E., Hasse, C., Lorenz, W., \& Rothmund, M. (1999). [Validation of a diagnostic scoring system (Ohmann score) in acute appendicitis] Der Chirurg; Zeitschrift für alle Gebiete der operativen Medizen, 70(7), 777-83; discussion 784. 


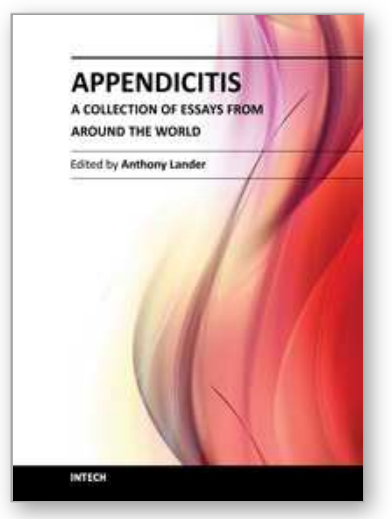

\author{
Appendicitis - A Collection of Essays from Around the World \\ Edited by Dr. Anthony Lander
}

ISBN 978-953-307-814-4

Hard cover, 226 pages

Publisher InTech

Published online 11, January, 2012

Published in print edition January, 2012

This book is a collection of essays and papers from around the world, written by surgeons who look after patients of all ages with abdominal pain, many of whom have appendicitis. All general surgeons maintain a fascination with this important condition because it is so common and yet so easy to miss. All surgeons have a view on the literature and any gathering of surgeons embraces a spectrum of opinion on management options. Many aspects of the disease and its presentation and management remain controversial. This book does not answer those controversies, but should prove food for thought. The reflections of these surgeons are presented in many cases with novel data. The chapters encourage us to consider new epidemiological views and explore clinical scoring systems and the literature on imaging. Appendicitis is discussed in patients of all ages and in all manner of presentations.

\title{
How to reference
}

In order to correctly reference this scholarly work, feel free to copy and paste the following:

Graham Thompson (2012). Clinical Scoring Systems in the Management of Suspected Appendicitis in Children, Appendicitis - A Collection of Essays from Around the World, Dr. Anthony Lander (Ed.), ISBN: 978953-307-814-4, InTech, Available from: http://www.intechopen.com/books/appendicitis-a-collection-of-essaysfrom-around-the-world/clinical-scoring-systems-in-the-management-of-suspected-appendicitis-in-children

\section{INTECH}

open science | open minds

\author{
InTech Europe \\ University Campus STeP Ri \\ Slavka Krautzeka 83/A \\ 51000 Rijeka, Croatia \\ Phone: +385 (51) 770447 \\ Fax: $+385(51) 686166$ \\ www.intechopen.com
}

\author{
InTech China \\ Unit 405, Office Block, Hotel Equatorial Shanghai \\ No.65, Yan An Road (West), Shanghai, 200040, China \\ 中国上海市延安西路65号上海国际贵都大饭店办公楼 405 单元 \\ Phone: +86-21-62489820 \\ Fax: +86-21-62489821
}


(C) 2012 The Author(s). Licensee IntechOpen. This is an open access article distributed under the terms of the Creative Commons Attribution 3.0 License, which permits unrestricted use, distribution, and reproduction in any medium, provided the original work is properly cited. 